\title{
France's 2020 Report Card on Physical Activity and Sedentary Behaviors in children and youth: Results and Progression
}

\author{
Fillon $\mathrm{A}^{1,2}$, Genin $\mathrm{P}^{1,2}$, Larras $\mathrm{B}^{1}$, Vanhelst $\mathrm{J}^{3}$, Luiggi $\mathrm{M}^{4}$, Aubert $\mathrm{S}^{5}$, Verdot $\mathrm{C}^{6}$, Rey $\mathrm{O}^{7}$, Lhuisset \\ $L^{8}$, Bois $\mathrm{J}^{1,8}$, Fearnbach $\mathrm{N}^{12}$, Duclos $\mathrm{M}^{1,9,10,11}$, Thivel $\mathrm{D}^{1,2}$.
}

\footnotetext{
1National Observatory for Physical Activity and Sedentary behaviors (ONAPS), Clermont-Ferrand, France. ${ }^{2}$ Clermont Auvergne University, EA 3533, Laboratory of the Metabolic Adaptations to Exercise under Physiological and Pathological Conditions (AME2P), CRNH Auvergne, Clermont-Ferrand, France.

${ }^{3}$ Inserm U1286 - INFINITE - Institute for Translational Research in Inflammation CIC 1403 - centre d'Investigation Clinique Centre Hospitalier et de recherche Universitaire (CHRU) de Lille Université de Lille, Lille, France

${ }^{4}$ Institut national du sport de l'expertise et de la performance, Pôle Performance, Unité Recherche et Laboratoire SEP, Paris, France.

${ }^{5}$ Healthy Active Living and Obesity Research Group, Children's Hospital of Eastern Ontario Research Institute, Ottawa, Ontario, Canada

${ }^{6}$ Équipe de surveillance et d'épidémiologie nutritionnelle (Esen) ; Direction des maladies non-transmissibles et traumatismes (DMNTT) - Santé publique France, Université Paris 13 - Sorbonne Paris Nord, Centre de recherche en Épidémiologie et Statistiques (CRESS), Bobigny, France

${ }^{7}$ Institut des sciences du mouvement, UMR CNRS 7287, Structure Fédérative d'Études et de Recherches en Éducation de Provence, FED 4238, Aix-Marseille Université, Marseille, France.

${ }^{8}$ Universite de Pau \& des Pays de l'Adour, e2s UPPA, MEPS, Tarbes, France.

${ }^{9}$ INRAE, UMR 1019, Clermont-Ferrand, France.

${ }^{10}$ University Clermont 1, UFR Medicine, Clermont-Ferrand, France.

${ }^{11}$ Department of Sport Medicine and Functional Explorations, Clermont-Ferrand University Hospital, G. Montpied Hospital, Clermont-Ferrand, France.

${ }^{12}$ Pennington Biomedical Research Center, Baton Rouge, LA, USA.
}

\section{Abstract}

Background: There is an alarming and constant worldwide progression of physical inactivity and sedentary behaviors in children and adolescents. The present paper summarizes findings from France's 2020 Report Card on physical activity for children and youth, comparing its results to its two previous editions (2016 and 2018).

Methods: France's 2020 Report Card follows the standardized methodology established by the Active Healthy Kids Global Matrix, grading 10 common physical activity indicators using the best available evidence. Grades were informed by national surveys, peer-reviewed literature, government and nongovernment reports, and online information.

Results: The expert panel awarded the following grades: Overall Physical Activity: D; Organized Sport Participation and Physical Activity: C-; Active Play: INC; Active Transportation: C-; Sedentary 
Behaviors: D-; Family and Peers: D-; Physical Fitness: D; School: B-; Community and the Built Environment: F; Government: C.

Conclusions: This 2020 edition of France's Report Card again highlights the alarming levels of physical activity and sedentary behaviors among French children and adolescents, calling for the development of effective national action. It also draws attention on the particular deleterious effects of the COVID19 confinement on youth's movement behaviors that significantly worsened the situation.

Key words: Adolescents, Sedentary Behaviors, Health, Active Transportation, Physical Activity Promotion

\section{Introduction}

Despite the continuously growing body of evidence that undoubtedly describes the beneficial effects of an active lifestyle on overall health from the youngest age ${ }^{1,2}$, studies describe persistently insufficient and declining levels of physical activity ${ }^{3-7}$ and an alarming progression of the time devoted to sedentary behaviors ${ }^{3-6,8-10}$.

In 2005, Canada lunched the first Report Card (RC) initiative, proposing a detailed analysis of national data on the physical activity and sedentary behaviors of Canadian youth ${ }^{11}$. This national initiative quickly influenced governmental policies, practices, and research orientations ${ }^{12}$, inspiring 15 countries to embrace this Report Card process in a coordinated way in 2014, leading to the creation of the international Global Matrix $1.0^{13}$. Gaining in interest and popularity, 38 countries took part in the Global Matrix 2.0 in $2016^{14}$, wherein France presented its first Report Card under the umbrella of the French National Observatory for Physical Activity and Sedentary Behaviors (ONAPS) ${ }^{15}$. As part of the Global Matrix 3.0 (involving 49 countries from 6 continents), the ONAPS proposed a 2018 updated version of the 2016 French report card, confirming very concerning levels of physical activity 
and sedentary behaviors among French children and youth ${ }^{16,17}$. Moreover, among the 10 physical activity indicators studied, Active Play, Family and Peers, and Community and Environment were found to have insufficient information at the national level. Although this 2018 Report Card placed France among the top $10 \%$ and 35\% countries regarding Physical Fitness and School indicators, respectively, the country was behind the majority of the European countries when it came to Organized Sport and Physical Activity, Active Transportation, and Sedentary Behaviors ${ }^{16,17}$.

While the Global Matrix 4.0 is planned to be released in 2022, the ONAPS proposes here an intermediary evaluation of the 10 physical activity indicators, particularly focusing on the effects of the unpredicted 2020 sanitary lock-down imposed to slow down the progression of the COVID-19 pandemic.

\section{Methods}

Following the classical and collective methodology established by the Global Alliance ${ }^{18}$ France's 2020 Report Card was prepared and conceived by an expert panel composed of members of the French National Observatory for Physical Activity and Sedentary Behaviors (ONAPS, www.onaps.fr), external and academic experts, and members from public health agencies (Santé Publique France). Briefly, the panel leader was responsible for integrating each expert's contribution and for writing the Report Card main document. All the authors contributed to identifying key data sources and synthesized the evidence from a range of national surveys, reviewed the entire document, and contributed to the grade for each indicator.

The 10 physical activity indicators selected at the international level by the Global Alliance were evaluated by the panel: Overall Physical Activity Levels, Organized Sport and Physical Activity, Active Play, Active Transportation, Sedentary Behaviors, Physical Fitness, Family and Peers, School, Community and Environment, and Governmental and Institutional Implication. 
87 The expert panel first connected in March 2020 and indicators were assigned to specific members of

88 the panel according to their area of interest and expertise. Each expert (or group of experts), supported by the operative agents of the ONAPS, compiled the best available evidence for 5 - to 17 year-old children and adolescents, performed an objective analysis, and wrote the RC section specific to their indicator. Based on each expert report, grades were collectively discussed and assigned in November 2020. Each indicator evaluation with quantitative data was graded using the standardized benchmarks and grading scheme provided by the AHKGA (Active Healthy Kids Global Alliance) ${ }^{18}$. A new grading scheme was developed and used when it came to indicators with more qualitative information and the need to acknowledge the degree of investment of actors (such as the governmental implication or Community and Environment indicators), as previously suggested ${ }^{19}$.

97 This adapted scheme is presented in Figure 1. As part of this 2020 Report Card, a particular focus was on the physical activity and sedentary behaviors of children and adolescents during the COVID-19 related confinement. While the available data were analyzed and discussed in the report, no grade was assigned to this special section. 
$81-100 \%$

A large majority of children and adolescents

\section{$61-80 \%$}

Above half of the children and adolescents

\section{$41-60 \%$}

About half of the children and adolescents

\section{$21-40 \%$}

Less than half of the children and adolescents

\section{$0-20 \%$}

A very low proportion of children and adolescents

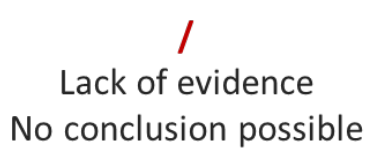

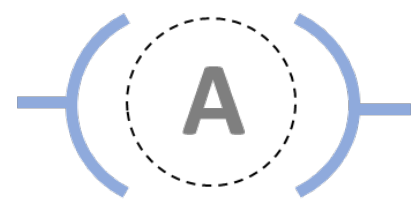
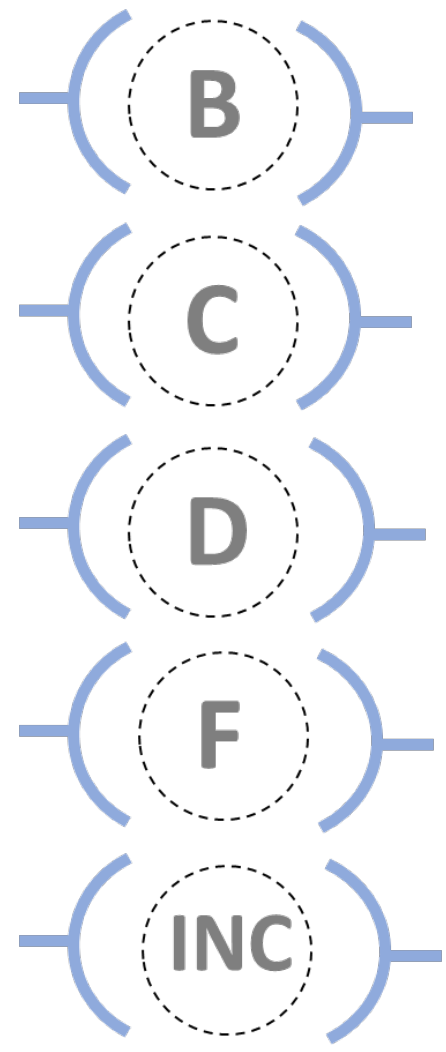

Very high level of evidence

High number of actions and plans with great and detailled evaluations

\section{Great level of evidence}

Several actions and plans with appropriate and well documented evaluation

\section{Correct level of evidence}

Several actions and plans that require a better evaluation

\section{Insufficient evidence}

Too few initiative and evaluation too low

\section{Level of evidence too low}

Few initiatives and no evaluation

\section{No evidence}

Lack of information or not concluant

Figure 1: Grading system adapted from the AHKGA (adapted from Aubert et al., 2018) ${ }^{18}$.

\section{Results and discussion}

Table 1: Evolution of the French Report Card grades from 2016 to 2020 for each physical activity indicator.

\section{Indicators}

2016

2018

2020

Overall Physical Activity

INC

$\mathrm{D}$

D

Organized Sport and Physical Activity

D

C-

C-

Active Play

NA INC INC




\begin{tabular}{|lccc|}
\hline Active Transportation & D & C- & C- \\
\hline Sedentary Behaviors & D & D- & D- \\
\hline Physical Fitness & NA & B- & D \\
\hline Family and Peers & INC & INC & D- \\
\hline School & B & B & B- \\
\hline Community and Environment & INC & INC & F \\
\hline Government & INC & C & C \\
\hline Average & & & \\
\hline
\end{tabular}

Note: $\mathrm{NA}=$ not assigned; $\mathrm{INC}=$ incomplete grade .

Overall Physical Activity: D

Based on the available data gathered, $50.7 \%$ of French boys and $33.3 \%$ of girls aged $6-17$ years old reached the physical activity guidelines (of 60 minutes of moderate to vigorous PA per day), with proportions declining with age and time, especially at the time of puberty. About $70 \%$ of boys and $56 \%$ of girls aged $6-10$ years old kids met the PA recommendations, compared to $34 \%$ and $20 \%$ between 11 to 14 years, and $40 \%$ and $16 \%$ between 15 and 17 years old, respectively ${ }^{20}$. The HBSC survey indicates that between 2014 and 2018, the percentage of 11-year-old girls meeting the guidelines declined from $25 \%$ to $17 \%$,compared to a drop from $11 \%$ to $9 \%$ in boys ${ }^{21}$. In 13 -year-old girls and boys, the proportion of youth meeting PA recommendations dropped from $16 \%$ to $14 \%$ and from $9 \%$ to $7 \%$, respectively. Similarly, rates dropped from $14 \%$ to $11 \%$ and $6 \%$ to $4 \%$ among 15 years old boys and girls, respectively. Girls, compared with boys, showed a greater decline in PA levels from 11 years of age, particularly for moderate-to-vigorous PA. 
were already considered in the 2018 RC. However, these were updated in 2020 with regards to the Esteban's data ${ }^{22}$ and HBSC 2017-2018 surveys ${ }^{21}$.

While the 2016RC concluded that there was a lack of evidence to properly and objectively evaluate this indicator (proposing then the grade "INC"), the 2018RC committee determined that sufficient data was available to assign the grade of " $\mathrm{D}$ ". Two years later, although some new data are available, the status of the overall physical activity level of children and adolescents in France remains worrying, and the expert panel maintained a grade of " $D$ ".

Increasing our national efforts for a larger and more efficient national surveillance system is urgent given the dramatic evolution of the physical activity level of children and adolescents. As part of the 2020RC conclusions, the expert panel recommends the implementation of educational campaigns regarding the exact definition and components of physical activity and its overall health and social impact, addressed to both parents and kids, but also to all the actors in kids' lives (e.g., educators or coaches). It is also essential to increase the opportunities to be active, through urban and environmental strategies and facilities.

\section{Organized Sport and Physical Activity: C-}

As for the last two reports, the participation in organized sports was evaluated based on the number of sports licenses delivered by French sports federations after registration in sports clubs for children and youth (excluding licenses delivered for school-based organized sports). In 2018, 8.2 million children and adolescents were registered members of a sport federation, which corresponds to $50 \%$ of the total number of federative licenses in France. A total of $59.5 \%$ of these licenses concern boys. 10 to 14 year olds represent the highest number of licenses, with a progressive decline after 14 years in both boys and girls, regardless of the type of sport. Between 2017 and 2018, the number of licenses across all federations combined declined by 761,601 among kids under 9 years old, 168,128 in 10 to 14 years old children, and 42,591 in adolescents aged 15 to 19 years old. 
A grade of " $D$ " was attributed to this indicator in 2016, and upgraded to a "C-" in 2018. The 2020 Report Card expert panel collectively decided to maintain this grade of "C-". Indeed, the trends and conclusions provided by available literature remain identical to what was observed two years ago.

As already underlined in 2018 , the available data do not provide any information concerning the dose, frequency, and intensity of activity during organized sports, which should be assessed ${ }^{16}$. This would inform the extent to which these federative practices contribute to the overall level of physical activity of our children and adolescents. Our committee encourages the development of new sport federations that would attract more youth, especially for girls, as well as the development of multiactivity licenses by federations. Further research is also needed to identify the potential barriers to accessing organized sport and physical activity for French children and youth, and if there is equal opportunity for participation in affordable and appealing activities across different territories (rural versus urban), genders, socio-economic levels, and sporting abilities.

\section{Active Play: INC}

While this indicator was not included in the RC analysis back in 2016, the 2018 RC pointed out a lack of evaluation and available evidence for active play in France (grade "NC"). National surveys (ESTEBAN 2014-2016 and Inca 3) reported the only available data showing that only $38 \%$ of boys and $39.3 \%$ of girls aged $6-10$ years old reported engaging in outdoor active play every school day, and $32.2 \%$ of boys and $33.2 \%$ of girls also reported playing outdoors on non-school days ${ }^{22}$. Unfortunately, the present 2020 analysis did not find any more recent evidence regarding this indicator and decided to maintain the grade " $N C^{\text {". }}$

This lack of national evaluation of active play indicator is not specific to France, with the majority of the Global Matrix 3.0 countries unable to evaluate this indicator in 2018 due to missing evidence ${ }^{16}$. While there is still a need for an international consensus on the definition of active play, future surveys and studies should include simple question to parents to estimate the engagement of 
children in active play and estimate the contribution to their overall physical activity level. Methodological studies should be conducted to develop reliable and validated tools to properly assess active play in children.

\section{Active Transportation: $\mathrm{C}$ -}

According to national data previously collected within the Esteban survey, $40 \%$ of children aged $6-10$ years old use active transportation to go to school ( $35 \%$ of boys and $45 \%$ of girls) ${ }^{22}$, and $43 \%$ of 11 to 14 year olds use active transportation to reach their school ( $42 \%$ of boys and $44 \%$ of girls) ${ }^{23}$. While $97 \%$ of parents declare that safety is among the top rated criteria to choose the mode of transportation to school for their child, $55 \%$ admit that the lack of security is among the primary reasons not to choose active transportation. While local administrations have started to increase their annual budget allocated to the development of cycle lanes, securing additional safe walking paths and bike lanes must be a priority. Overall, the global cycling and walking infrastructures, including on-road and off-road paths with physical separation from vehicles, should be improved and further developed.

In France, as in most countries, the use of active transportation in youth is primarily assessed through surveys related to school, the full spectrum of active commuting opportunities should be considered (travels to parks, leisure activities, shopping, etc.).

Although the grade attributed to this indicator improved between 2016 and 2018, progressing from "D" to "C-", the 2020 RC expert panel collectively considered that the lack of new evidence, as well as the distance and perspective regarding the actions/strategies initiated did not allow us to modify this grade and maintained the grade "C-".

\section{Sedentary Behaviors: D-}


Nearly 3 of every 4 French school-aged children exceed the recommended limit of 2 hours of screen exposure per day, with half of children reaching at least 3.5 hours per day and $10 \%$ exceeding 6 hours per day. During weekends, $93 \%$ of these children exceed 2 hours of screen time per day, $50 \%$ reach at least 6 hours, and $10 \%$ reach more than 11 hours. These data collected among school children and adolescents confirm the alarming situation captured in national surveys ${ }^{22,23}$ indicating that French children and adolescents spend an average of 4 hours per day in front of a screen. Only $28.3 \%$ of boys and $41.5 \%$ of girls aged $6-10$ years old, $16.3 \%$ of boys and $17.3 \%$ of girls aged $11-14$ years, and $2.6 \%$ of boys and $13.7 \%$ of girls aged $15-17$ years old meet the guidelines for less than 2 hours per day in front of screens ${ }^{20,22,23}$.

While the present surveys predominantly ask about the use of TV, computers, and video games, our national surveys should also include tablets and smartphones in their evaluations. Moreover, there is a clear need at the national and international level to develop a reliable and validated questionnaire to better evaluate this sedentary time and its characteristics (frequency, duration, and timing during the day). These alarming statistics highlight an urgent need for policies aimed at decreasing recreational screen time among youth, but also to better educate the general population about the deleterious short and long term effects of sedentary time across the lifespan. Due to the lack of new or higher quality data since the 2018 RC expert panel downgraded this indicator from " $D$ " (2016) to "D-“ (2018), the 2020 grade for sedentary behaviors remains "D-“.

\section{Physical Fitness: D}

While this indicator was not evaluated as part of the first 2016RC, the 2018 expert panel noted that French children and adolescents had a moderately good overall physical fitness and attributed the grade "B-" to the indicator. This evaluation was based on data collected among a large sample of children and youth aged 10-15 years old, between 2009 and $2013^{24}$. Although our 2018RC clearly underlined the need for updated and more systematic evaluation of this indicator, limited recent 
data were available for the current evaluation process. Recent findings describe changes in muscle strength, cardiorespiratory endurance, speed, agility, and coordination between 2010 and 2013 of 516 children who were $7.7 \pm 0.4$ years old at the start of the study ${ }^{25}$. These results show a significant reduction of the overall fitness of the kids who maintained a healthy weight from 2010 to 2013. Children who were initially healthy weight in 2010 but who developed overweight in 2013 show a significant reduction of their cardiorespiratory fitness, agility, and coordination. Coordination and agility were significantly reduced among children who initially had overweight/obesity in 2010 and achieved a healthy weight by 2013. Finally, overall fitness was significantly reduced among those who had persistent overweight/obesity from 2010 to 2013 (ref). Although these results were published in 2020, the data were collected between 2010 and 2013, and no more recent strong evidence was available. Based on these alarming results and observations made in the RC2018, coupled witj the lack of new data, the expert panel makes an urgent call for new national fitness evaluation campaigns on a regular basis. Physical fitness in children and adolescents is a determinant of physical and mental health and strongly associated with long-term health outcomes as they age into adulthood. We herein highlight the need for national campaign and educational strategies for children and families, in combination with environmental approaches to promote physical activity and then fitness. Altogether, these observations led the 2020RC expert panel to attribute the grade of " $D$ " to this indicator.

\section{Family and Peers: D-}

The two previous edition of the RC (2016-2018) based their analysis on only two regional studies that examined the physical activity level of parents ${ }^{26,27}$, and clearly concluded that the level of available evidence was not complete enough to attribute a letter grade to the Family and Peers indicator ("NC"). There have been some new studies investigating the role of parents and peers on children's physical activity since the last evaluation ${ }^{28-31}$. One study found that the physical activity level of 
French adolescents is positively associated with the perception of their parents' activity levels

250

251

252

253

254

255

256 (Langlois, Omorou, Vuillemin, Briançon, \& Lecomte, 2017). Another study conducted among football players and coaches also underlines the role played by children's sport instructors or coaches (Van Hoye, Heuzé, Van den Broucke, \& Sarrazin, 2016). In that study the engagement and implication in youth's practice of sport is positively associated with the reported reinforcement of theirself-esteem, respect of others, and pleasure by coaches (Van Hoye, Heuzé, Van den Broucke, \& Sarrazin, 2016). As already noted in the 2018 RC, evidence shows that higher family socio-economic status is associated with higher physical activity and lower sedentary time in children and adolescents ${ }^{22}$.

Although the expert panel upgraded this indicator to "D-" for the 2020 edition of the RC, they collectively recommend additional work in this area. We must also disseminate more information regarding the role of parents and peers on children and adolescent's health behaviors. Importantly, parent and peer influence can come in the form of education, but also through simply modeling health behaviors and providing social support during activities.

\section{School: B-}

As previously detailed in the two previous iterations of France's Report Card, three hours per week of physical education (PE) are recommended nationally for children attending primary schools (6-10 years-old). In secondary schools (11-14 years-old), PE covers four hours per week in grade 6 students and three to four hours per week in older students. High school students (15-18 years old) get two hours per week of PE. The 2020RC notes the recurrent and alarming issue of PE exemption. In 2019, a national survey reported the permanent exemption rates for about $8.5 \%$ of girls following a professional curriculum. This report also indicates that this permanent exemption rate is at least twice as high in girls compared with boys ${ }^{32}$. While these statistics concerned children and adolescents that do not practice PE at all, further evaluations of temporary and partial exemption and the reasons for these assignments are needed. In addition to the PE lessons included school curricula, extra-curricular physical activities are offered to students. In elementary and primary 
school children, $20 \%$ and $80 \%$ of pupils engaged in these extra-curricular activities, respectively, which corresponds to $12.4 \%$ of the student population. In 2018-2019, a total of 1,179,261 secondary school students are engaged in extra-curricular physical activities, $41.75 \%$ girls and $58.25 \%$ boys, which corresponding to a decline of $0.67 \%$ compared to the previous year. The number of licenses declined more sharply in older students ${ }^{33}$. Further research is needed to better understand the decline of the youth involvement in PE and school-based activities with age, especially among girls. We reinforce the recommendations from 2016 and 2018. As in 2018, we collectively believe that the school environment could be an ideal setting to promote overall physical activity and to create a culture of healthy movement behaviors beyond those that take place at school. We encourage the continued development of new school policies to increase physical activity opportunities and ensure that a greater proportion of youth would meet the WHO's physical activity guidelines. Four national programs will encourage the participation in weekly physical activities leading up to the Olympic games of 2024 in Paris. This kind of initiative should be promoted more strongly. There is an increasing body of evidence clearly showing the feasibility and beneficial effects of active classrooms, using activity breaks or active desks, and more field experiments should be conducted to properly evaluate their effectiveness. In line with the two previous RC underlining the central and crucial role played by the school setting on physical activity in youth (with a grade of "B" in both 2016 and 2018), the 2020RC expert panel attributed the "B-" grade to this indicator.

\section{Community and Environment: $F$}

As in the previous RC, most of the available evidence regarding this indicator relates to cycling paths. In $2019,1.36 \mathrm{~km}$ per 1000 inhabitants have been created or rearranged, compared to $1.0 \mathrm{~km}$ per 1000 in 2016 . A total of $66 \%$ of public roads have now a speed limit of $30 \mathrm{~km} / \mathrm{h}$ to improve the safety of cycle users, and $26 \%$ of the roads with a speed limit of $50 \mathrm{~km} / \mathrm{h}$ are equipped with physically identified cycling paths (enquête CVCT, 2019 (ref). Approximately 40\% of current cyclists report that 
the local safety conditions have positively improved between 2017 and 2019. This finding varies depending on the size of the city, with $27 \%$ of cyclists in cities of less than 20,000 inhabitants, and $56 \%$ of cyclists in cities above 200,000 habitants (Baromètre 2019 des villes cyclables de la FUB). According to the Cycling Cities and Territory Club (CVTC), the budget dedicated to the development of a "cycling strategy" by urban collectivity increased from 7.32 euros per inhabitant in 2016 to 9.26 euros per inhabitant in 2019. In 2019, $91 \%$ of their city members had a specific and official plan for increased cycle use, versus $83 \%$ in 2016 . While these efforts are encouraging, they must be sustained to promote the use of cycles in urban areas. We need more evaluations on the progression of sports facilities, playground areas, and green areas, as noted in the previous editions of the RC. While the development of cycling facilities and opportunities is an important source of physical activity at the community level, other types of community programs and infrastructure should be developed. As part of the heritage strategy of the 2024 Paris Olympic Games, the organizing committee has created a working group to develop new "active designs" for sport infrastructures and public spaces, with a goal to enhance physical activity in the general population. The2016 and 2018 RC had insufficient evidence to assign a letter grade to the Community and Environment indicator. This year, the " $\mathrm{F}$ " grade has been, highlighting the need for new interventions and projects with appropriate assessment to improve this RC evaluation. The 2020RC committee and the French ONAPS call for action and new initiatives to promote PA at the community level, and for collection of qualitative and quantitative data on the response to these efforts.

\section{Government: $C$}

New national plans and strategies have been developed since 2018 to promote physical activity and combat excessive sedentary behaviors from the youngest age. The 2018-2022 National Health Strategy includes the promotion of a regular physical activity coupled with a reduction in sedentary time as one of its objectives. It includes a specific section focusing on health in youth, with particular 
325

attention to the excessive use of screens in young people. The Priority Prevention Plan that started in 2018 also considers regular physical activity as a primary strategy to fight pediatric overweight/obesity and related complications. Three main actions related to physical activity are part of this plan: i) swimming lessons from the youngest age; ii) cycling lessons; iii) curriculum development combining school classes in the morning with physical practice in the afternoon. The first two axes were established to guarantee that children can swim and bike safely (as two modes to improve PA), while the afternoon activities are implemented to help youth discover new activities and improve fitness. An inter-ministries National Sport and Health Strategy 2019-2024 has been developed, aiming at creating a national culture of health movement behaviors. One the main missions is to develop the practice of physical activity among school children. In 2019, the fourth National Nutrition and Health Plan was launched (PNSS 2019-2023), including several objectives for the promotion and encouragement of active mobility, overall physical activity, physical education, and a reduction of sedentary behaviors in children and parents. These efforts led to several initiatives, including the deployment of the formerly evaluated ICAPS program ${ }^{34,35}$, as well as the creation of a "2024 Generation label" in conjunction with the organization of the 2024 Olympic Games in Paris.

As noted in 2018, there is still a lack of data to quantify the level of leadership and commitment from the French government in providing physical activity opportunities for all youth. Although several actions and plans have been initiated and launched, the evaluation of effectiveness and cost-benefit analysis is still to be determined. The grade for this indicator improved from "INC" to "C" from 2016 to 2018 , and our 2020 expert panel decided to maintain the "C" grade. We are hopeful for objective evaluation of these national initiatives for our next edition.

\section{0: Year of the COVID-19 confinements.}


349 The addition of a 2020 RC for physical activity and sedentary behaviors must consider the unique 350 situation generated by the COVID-19-related confinements, having significantly affected movement 351 behaviors. The ONAPS, in the early days of the first confinement (March 2020), launched a national 352 survey examining the potential changes induced by the lock-down on population-level physical 353 activity and sedentary behaviors ${ }^{36}$. Complete data were collected for 22,895 participants, including 3541588 6-10 year olds, 4903 adolescents (11-18 year olds) and 348 children below 6 years old. Among 355 very young kids (below 6 years), 50.3\% increased their physical activity levels during confinement, $35625 \%$ decreased, and $24.7 \%$ maintained their PA levels. The access to an outdoor area was positively 357 associated with the maintenance or increase in physical activity ${ }^{37}$. However, $60.4 \%$ of these young 358 children increased their screen time, and $51 \%$ of parents reported that this increased screen 359 exposure was linked to the necessity to work from home ${ }^{37}$. About $42 \%$ of children $6-10$ years and $36058.7 \%$ of adolescents decreased physical activity during the confinement, a decline that was more 361 pronounced among initially active youth. The Figure 2 illustrates these changes among children and adolescents 6 to 17 years old who were initially active and inactive. Concerning screen time, $62 \%$ of 6-10 year old children and $68.9 \%$ of adolescents experienced an increase in exposure to screens ${ }^{38}$. 


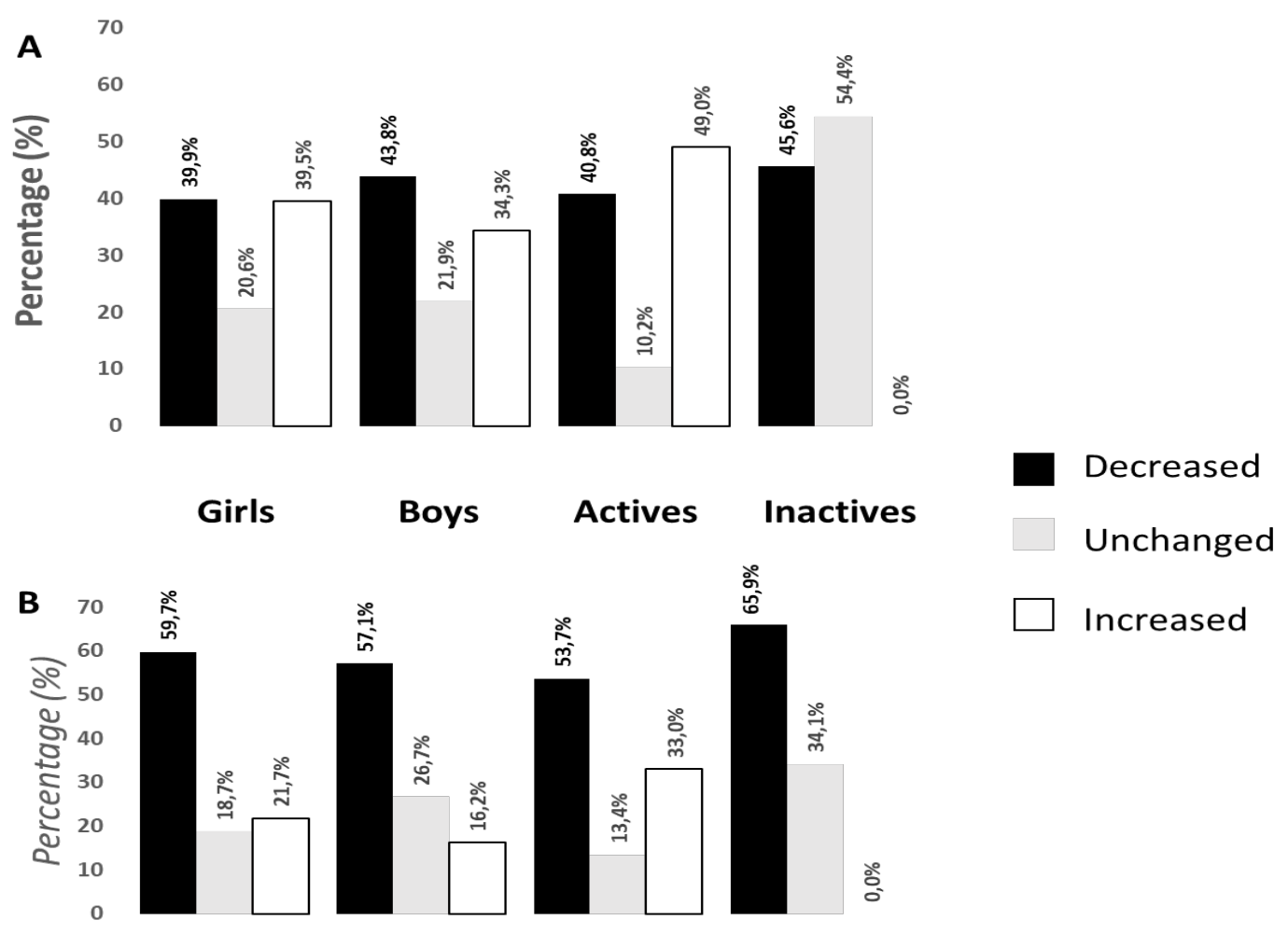

366 Figure 2: Declared evolution of the physical activity level of 6-10 years old (A) and 11-17 years old (B) children and adolescents during the first 2020 French COVID-19 related confinement (according to Chamboniièere et al., 2021).

While these results are in line with what has been observed at the international level, they also highlight the fact that being active does not prevent children and adolescents from other deleterious effects of such a confinement period. Recommendations have been formulated by the ONAPS in the

373 likely event of additional lock-downs in the future ${ }^{39}$. We must ensure that the behavioral changes 374 induced by such periods do not worsen the alarming prevalence of physical inactivity and sedentary behaviors in youth.

\section{Conclusions}


The 2020 French Report Card expert panel presents a third edition of the Report Card following its $2016^{15}$ and $2018^{16}$ evaluations. While insufficient data remained available to grade the Active Play indicator, all others were graded. This allowed us to evaluated three new indicators which could not previously be rated (Active Play, Family and Peers, Community and Environment). Based on our 2020 analysis, while most of the indicators show a relative stagnation of their evaluation (as shown in table $X)$, physical fitness has been downgraded from "B-" to " $D$ " due to the lack of updated evidence. Although stable, our conclusions remain that levels of physical activity and sedentary behaviors among French children and youth are very concerning (with respective grades of "D" and "D-“). Despite slight grade changes on individual metrics, the overall 2020RC grade remains stable compared to our 2018 edition with "C-“ (RC2016 “D”). The next coordinated Global Matrix 4.0 will be launched in 2022, allowing for international comparison at that time.

The present evaluation of PAL and SB did not consider the context of the COVID-19 confinement that dramatically affected both indicators in French children and adolescents, similarly to findings reported at the international level,. We confirm the urgent need for efficient public health strategies, developed and implemented at the national level, to address this physical inactivity crisis. National plans and strategies have been developed and launched to promote overall PA and fight against excessive sedentary behaviors since our previous RC edition, and we collectively hope that their evaluation will provide us with positive results supporting improvements of our kids' movement behaviors.

Acknowledgements. The authors want to thank the MatMut insurance mutuality for its support as well as HealthWay for coordinating the France Report Card process.

Founding source. The authors want to thank the MatMut insurance mutuality for its support as well as HealthWay for coordinating the France Report Card process.

Declaration of interest. The authors have no conflict of interest to disclose. 
1. Poitras VJ, Gray CE, Borghese MM, et al. Systematic review of the relationships between objectively measured physical activity and health indicators in school-aged children and youth. Appl Physiol Nutr Metab. 2016;41(6 Suppl 3):S197-239. doi:10.1139/apnm-2015-0663

2. Janssen I, Leblanc AG. Systematic review of the health benefits of physical activity and fitness in school-aged children and youth. Int J Behav Nutr Phys Act. 2010;7:40. doi:10.1186/1479-5868-740

3. Brodersen NH, Steptoe A, Boniface DR, Wardle J. Trends in physical activity and sedentary behaviour in adolescence: ethnic and socioeconomic differences. Br J Sports Med. 2007;41(3):140-144. doi:10.1136/bjsm.2006.031138

4. Kalman M, Inchley J, Sigmundova D, et al. Secular trends in moderate-to-vigorous physical activity in 32 countries from 2002 to 2010: a cross-national perspective. Eur J Public Health. 2015;25 Suppl 2:37-40. doi:10.1093/eurpub/ckv024

5. Booth VM, Rowlands AV, Dollman J. Physical activity temporal trends among children and adolescents. J Sci Med Sport. 2015;18(4):418-425. doi:10.1016/j.jsams.2014.06.002

6. Dollman J, Norton K, Norton L. Evidence for secular trends in children's physical activity behaviour. Br J Sports Med. 2005;39(12):892-897; discussion 897.

doi:10.1136/bjsm.2004.016675

7. Guthold R, Stevens GA, Riley LM, Bull FC. Worldwide trends in insufficient physical activity from 2001 to 2016: a pooled analysis of 358 population-based surveys with 1.9 million participants. Lancet Glob Health. 2018;6(10):e1077-e1086. doi:10.1016/S2214-109X(18)30357-7

8. Sigmund E, Sigmundová D, Badura P, Kalman M, Hamrik Z, Pavelka J. Temporal Trends in Overweight and Obesity, Physical Activity and Screen Time among Czech Adolescents from 2002 to 2014: A National Health Behaviour in School-Aged Children Study. Int J Environ Res Public Health. 2015;12(9):11848-11868. doi:10.3390/ijerph120911848

9. Bucksch J, Sigmundova D, Hamrik Z, et al. International Trends in Adolescent Screen-Time Behaviors From 2002 to 2010. J Adolesc Health. 2016;58(4):417-425. doi:10.1016/j.jadohealth.2015.11.014

10. Corder K, Sharp SJ, Atkin AJ, et al. Change in objectively measured physical activity during the transition to adolescence. Br J Sports Med. 2015;49(11):730-736. doi:10.1136/bjsports-2013093190 
12. Tremblay MS, Barnes JD, Cowie Bonne J. Impact of the Active Healthy Kids Canada report card: a 10-year analysis. J Phys Act Health. 2014;11 Suppl 1:S3-S20. doi:10.1123/jpah.2014-0167

13. Tremblay MS, Gray CE, Akinroye K, et al. Physical activity of children: a global matrix of grades comparing 15 countries. J Phys Act Health. 2014;11 Suppl 1:S113-125. doi:10.1123/jpah.20140177

14. Tremblay MS, Barnes JD, González SA, et al. Global Matrix 2.0: Report Card Grades on the Physical Activity of Children and Youth Comparing 38 Countries. J Phys Act Health. 2016;13(11 Suppl 2):S343-S366. doi:10.1123/jpah.2016-0594

15. Aucouturier J, Ganière $C$, Aubert $S$, et al. Results From the First French Report Card on Physical Activity for Children and Adolescents. J Phys Act Health. 2017;14(8):660-663. doi:10.1123/jpah.2017-0046

16. Aubert S, Aucouturier J, Ganière C, et al. Results from France's 2018 Report Card on Physical Activity for Children and Youth. J Phys Act Health. 2018;15(S2):S360-S362. doi:10.1123/jpah.2018-0511

17. Aubert S, Aucouturier J, Vanhelst J, et al. France's 2018 Report Card on Physical Activity for Children and Youth: Results and International Comparisons. J Phys Act Health. 2020;17(3):270277. doi:10.1123/jpah.2019-0241

18. Aubert S, Barnes JD, Abdeta C, et al. Global Matrix 3.0 Physical Activity Report Card Grades for Children and Youth: Results and Analysis From 49 Countries. J Phys Act Health. 2018;15(S2):S251S273. doi:10.1123/jpah.2018-0472

19. Ward MR, Tyler R, Edwards LC, Miller MC, Williams S, Stratton G. The AHK-Wales Report Card 2018: Policy Measures - is it possible to "score" qualitative data? Health Promot Int. Published online November 9, 2020. doi:10.1093/heapro/daaa118

20. Verdot C, Salanave B, Deschamps V. Activité physique et sédentarité dans la population française. Situation en 2014- 2016 et évolution depuis 2006-2007. Bull Epidémiol Hebd. 2020;(15):296-304.

21. Inchley J, Currie D, Budisavljevic S, Torsheim T, Jåstad A, Cosma A et al., editors. Spotlight on adolescent health and well-being. Findings from the 2017/2018 Health Behaviour in School-aged Children (HBSC) survey in Europe and Canada. International report. Volume 2. Key data. Copenhagen: WHO Regional Office for Europe; 2020.

22. Équipe de surveillance et d'épidémiologie nutritionnelle (Esen). Étude de Santé Sur I'environnement, La Biosurveillance, I'activité Physique et La Nutrition (Esteban), 2014-2016. Volet Nutrition. Chapitre Corpulence. 2e Édition. Santé publique France; 2020:1-58. www.santepubliquefrance.fr

23. Anses. INCA 3 en image - Les Français, l'activité physique et la sédentarité | Anses - Agence nationale de sécurité sanitaire de l'alimentation, de l'environnement et du travail. Accessed January 13, 2021. https://www.anses.fr/fr/content/inca-3-en-image-les-fran\%C3\%A7aislactivit\%C3\%A9-physique-et-la-s\%C3\%A9dentarit\%C3\%A9

24. Vanhelst J, Labreuche J, Béghin L, et al. Physical Fitness Reference Standards in French Youth: The BOUGE Program. J Strength Cond Res. 2017;31(6):1709-1718. doi:10.1519/JSC.0000000000001640 
25. Vanhelst J, Ternynck C, Ovigneur H, Deschamps T. [Tracking of physical fitness during chilhood: Longitudinal findings from the Diagnoform program]. Rev Epidemiol Sante Publique. 2020;68(3):163-169. doi:10.1016/j.respe.2020.04.052

26. Thibault H, Contrand B, Saubusse E, Baine M, Maurice-Tison S. Risk factors for overweight and obesity in French adolescents: physical activity, sedentary behavior and parental characteristics. Nutrition. 2010;26(2):192-200. doi:10.1016/j.nut.2009.03.015

27. Wagner A, Klein-Platat C, Arveiler D, Haan MC, Schlienger JL, Simon C. Parent-child physical activity relationships in 12-year old French students do not depend on family socioeconomic status. Diabetes Metab. 2004;30(4):359-366. doi:10.1016/s1262-3636(07)70129-5

28. Bernal C, Lhuisset L, Fabre N, Bois J. School-Based Multi-component Intervention to Promote Physical Activity and Reduce Sedentary Time of Disadvantaged Children Aged 6-10 Years: Protocol for a Randomised Controlled Trial. Journal of medical Internet Research Protocols. Published online in press.

29. Cousson-Gélie F, Carayol M, Fregeac B, et al. The "great live and move challenge": a program to promote physical activity among children aged 7-11 years. Design and implementation of a cluster-randomized controlled trial. BMC Public Health. 2019;19(1):367. doi:10.1186/s12889019-6648-x

30. Langlois J, Omorou AY, Vuillemin A, Briançon S, Lecomte E, PRALIMAP Trial Group. Association of socioeconomic, school-related and family factors and physical activity and sedentary behaviour among adolescents: multilevel analysis of the PRALIMAP trial inclusion data. BMC Public Health. 2017;17(1):175. doi:10.1186/s12889-017-4070-9

31. Van Hoye A, Heuzé J-P, Van den Broucke S, Sarrazin P. Are coaches' health promotion activities beneficial for sport participants? A multilevel analysis. J Sci Med Sport. 2016;19(12):1028-1032. doi:10.1016/j.jsams.2016.03.002

32. Eduscol. L'évaluation Aux Baccalauréats, CAP et BEP de l'enseignement Général, Technologique et Professionnel En Education Physique et Sportive.; 2019. https://eduscol.education.fr/eps/examens/ComNat/rapport-cne-2019

33. UNSS. RAPPORT GÉNÉRAL 2018 - 2019.; 2020. https://unss.org/wpcontent/uploads/2020/02/RAPPORT_G\%C3\%89N\%C3\%89RAL_UNSS_2018_2019.pdf

34. Simon C, Wagner A, DiVita C, et al. Intervention centred on adolescents' physical activity and sedentary behaviour (ICAPS): concept and 6-month results. Int J Obes Relat Metab Disord. 2004;28 Suppl 3:S96-S103. doi:10.1038/sj.ijo.0802812

35. Simon C, Wagner A, Platat C, et al. ICAPS: a multilevel program to improve physical activity in adolescents. Diabetes Metab. 2006;32(1):41-49. doi:10.1016/s1262-3636(07)70245-8

36. Genin P, Dutheil F, Larras B, et al. Promoting physical activity and reducing sedentary time among tertiary workers: Position Stand from the French National Observatory for Physical Activity and Sedentary Behaviors (ONAPS). 2020 In press. Journal of Physical Activity and Health. Published online in press.

37. Fillon A, Lambert C, Tardieu M, et al. Impact of the COVID-19 confinement on movement behaviors among French young children ( $<6$ years old): Results from The ONAPS national survey. Pediatric Minerva. Published online under review. 
38. Chambonnière $\mathrm{C}$, Lambert $\mathrm{C}$, Tardieu M, et al. Effect of the COVID-19 confinement on Physical Activity and Sedentary Behaviors in French Children and Adolescents: new results from The ONAPS national survey. Pediatric Minerva. Published online under review.

39. Thivel D, Tardieu M, Genin P, et al. COVID-19-related national re-confinement: recommendations from the National French Observatory for Physical activity and Sedentary Behaviors (ONAPS). JPAH. Published online under review. 